\title{
Combining SGLT2 inhibitor and GLP-1 agonist: exaggerated weight loss in a morbidly obese patient with type 2 diabetes
}

\author{
KG NILWALA U JAYASINGHE, VERONICA J GREENER, MICHAEL D FEHER
}

\section{Introduction}

Obesity and type 2 diabetes are commonly seen together in current clinical practice. Morbid obesity and poorly controlled diabetes is often a therapeutic challenge. Management ideally needs to target insulin resistance and hormonal control mechanisms. When subcutaneous insulin is used in patients with obesity and type 2 diabetes, it exacerbates weight gain and thus a vicious cycle of worsening insulin resistance requires additional management strategies.

We report a case of exaggerated weight reduction with combination therapy of liraglutide and dapagliflozin. The patient achieved a loss in excess body weight (EBW) of $73.5 \mathrm{~kg}$ or $40.3 \%$ and a reduction in $\mathrm{HbA}_{1 c}$ from $83 \mathrm{mmol} / \mathrm{mol}(9.7 \%)$ to $36 \mathrm{mmol} / \mathrm{mol}(5.4 \%)$ in response to the combination therapy of oral dapagliflozin with subcutaneous liraglutide and concurrent discontinuation of subcutaneous insulin.

Key words: morbidly obese, weight reduction, SGLT2 inhibitor, GLP-1 agonist

\section{Background}

To date there are limited published data on the effectiveness of a combination of an SGLT2 inhibitor with GLP-1 agonist therapy in glucose lowering and weight reduction in type 2 diabetes. ${ }^{1}$ Both SGLT2 inhibitors and GLP-1 agonists have marked heterogeneity of response for both glucose and weight reduction, with some patients exhibiting a hyper-responder response. ${ }^{2}$ This case highlights the potential benefit of this combination in patients with type 2 diabetes and morbid obesity and suggests a new strategy for medical therapy to achieve marked weight loss and improve glycaemic control.

\section{Case report}

A 52-year-old man was referred for specialist opinion on man-

Beta Cell Diabetes Centre, Chelsea \& Westminster Hospital, London, UK

\section{Address for correspondence: Dr MD Feher}

Beta Cell Diabetes Centre, Chelsea \& Westminster Hospital,

369 Fulham Rd, London NW1 8LB, UK.

Tel: +44 (0)2087468134

E-mail: m.feher@chelwest.nhs.uk

Br J Diabetes 2016:16:138-139

http://dx.doi.org/10.15277//bjd.2016.092
Table 1 Improvements in clinical parameters over 1 year

\begin{tabular}{lll}
\hline Clinical parameter & Baseline & Changes at 1 year \\
Weight, kg & 209.5 & -73.5 \\
BMl, kg/m² & 61.2 & -21.5 \\
EBW, kg & 124 & -50 (loss of \\
& & $40.3 \% \mathrm{EBW})$ \\
Blood pressure, mmHg & $225 / 110$ & $-34 / 19$ \\
HbA 1 , mmol/mol (\%) & $83(9.7 \%)$ & $-47(-4.3 \%)$ \\
$\begin{array}{l}\text { Obstructive sleep apnoea } \\
\text { symptoms }\end{array}$ & Present & Absent
\end{tabular}

BMI, body mass index; EBW, excess body weight.

aging insulin-dependent diabetes. Diabetes was diagnosed 20 years previously following an episode of possible ketoacidosis and significant weight loss and treated with subcutaneous insulin. He weighed $209.5 \mathrm{~kg}$ (124 kg EBW) with a body mass index (BMI) of $61.2 \mathrm{~kg} / \mathrm{m}^{2}$. He reported lifelong problems with being overweight, which was exacerbated by insulin therapy. Despite biphasic isophane insulin 50 units twice daily and metformin, he had poor glycaemic control with $\mathrm{HbA}_{1 \mathrm{c}}$ of 83 $\mathrm{mmol} / \mathrm{mol}(9.7 \%)$ and complications of pre-proliferative retinopathy and peripheral neuropathy. His urine ketones were negative, as were anti-GAD and anti-islet cell antibodies. His C-peptide level was normal at $3.17 \mu \mathrm{g} / \mathrm{L}$. He had normal renal biochemistry with serum creatinine of $71 \mathrm{mmo} / \mathrm{L}$. Severe hypertension was evident at $225 / 110 \mathrm{mmHg}$, and clinical evidence of obstructive sleep apnoea and clinical signs of insulin resistance including skin tags at the posterior neck were observed.

In the presence of a clinical and biochemical phenotype of type 2 diabetes rather than type 1 , his insulin was initially reduced to 30 units. Due to gastrointestinal side-effects, immediate release metformin was switched to modified release metformin and over a period of months the insulin was withdrawn. Dapagliflozin $10 \mathrm{mg}$ once daily with subcutaneous liraglutide titrated up to $1.8 \mathrm{mg}$ once daily were commenced in addition to antihypertensive drugs.

Glycaemic control markedly improved to an $\mathrm{HbA}_{1 \mathrm{c}}$ value of $54 \mathrm{mmol} / \mathrm{mol}(8.7 \%)$ at 3 months, $43 \mathrm{mmol} / \mathrm{mol}(7.1 \%)$ at 6 months and $36 \mathrm{mmol} / \mathrm{mol}(5.4 \%)$ after 1 year. Most strikingly, a 
remarkable $73.5 \mathrm{~kg}$ (40.3\% EBW) weight loss was observed within 1 year of treatment, achieving a nadir of $136 \mathrm{~kg}$ (BMI $-39.7 \mathrm{~kg} / \mathrm{m}^{2}$ ) along with improvements in his blood pressure and resolution of obstructive sleep apnoea symptoms, despite his diet and physical exercise being unchanged throughout (Table 1).

\section{Discussion}

This case demonstrates the potential for inducing marked weight loss with improvements in glycaemic control through the combination of liraglutide, dapagliflozin and metformin. Our patient lost $73.5 \mathrm{~kg}$ of his weight or $40.3 \%$ EBW loss with the changes in medication without a significant change in his lifestyle. This degree of weight loss is usually seen following bariatric procedures. Currently available weight loss medications achieve on average a 5\% EBW loss. Liraglutide is well known for weight loss benefits and weight loss maintenance. ${ }^{3-5}$ Clinical trials demonstrated a weight loss of 3.7-8 kg after a 2-year period of liraglutide $3 \mathrm{mg}$ per day and a weight loss of $1.3-4.7 \mathrm{~kg}$ using 2.4 or $3.0 \mathrm{mg}$ daily in respective studies. ${ }^{3}$ Weight loss benefits were evident when liraglutide was combined with metformin and a sulphonylurea.6,7 Dapagliflozin also aided weight loss when added to metformin in patients with poorly controlled type 2 diabetes, ${ }^{8,9}$ with a small cohort exhibiting excessive weight loss. ${ }^{1}$

To our knowledge, this is the first reported case in a morbidly obese individual where the combination of GLP-1 agonists and SGLT2 was associated with marked weight loss and dramatic improvements in glycaemic control, comparable to surgical intervention.

There are limited reported data on the combination of SGLT2 inhibitors and GLP-1 agonists. ${ }^{1}$ One report on the combination of a SGLT inhibitor with other therapies in type 2 diabetes mellitus demonstrated an improvement in weight and glycaemic control and resulted in either dose reduction or cessation of other diabetes therapies in the treated cohort. ${ }^{1}$ Avoidance of pharmacokinetic interactions causing negligible effects on each other's plasma concentrations has been observed when SGLT2 inhibitors and other oral hypoglycaemic drugs are co-administered. ${ }^{10}$ In the absence of pharmacodynamic data on the interaction between SGLT2 inhibitors and GLP-1 agonists, we hypothesise that the two drugs may potentiate the weight loss effect when used synergistically.

Individual variations in weight loss response are known to occur with liraglutide, and genetic differences in GLP-1 receptors are considered to be associated with these responder differences. ${ }^{11}$ Our patient's heightened weight loss may be partly due to individual variation in response to either of the medications as a 'hyperresponder'. However, this patient's weight loss was maximised by the discontinuation of insulin.

In the management of patients with type 2 diabetes and morbid obesity, the combination of an SGLT2 inhibitor and GLP-1 agonist provides a pharmacological option to achieve improved clinical effect and possibly avoid the need for subcutaneous insulin.

\section{Conflict of interest None Funding sources None.}

\section{Key messages}

- Management of type 2 diabetes with morbid obesity is complex

- Combination of SGLT2 inhibitor and GLP-1 agonist in diabetes management may assist marked glucose and weight reduction in certain individuals

- Pharmacological "hyper-responders" may avoid bariatric procedures

\section{References}

1. McGovern AP, Dutta N, Munro N, Watters K, Feher M. Dapagliflozin: clinical practice compared with pre-registration trial data. Br J Diabetes Vasc Dis 2014;14:138-43. http://dx.doi.org/10.15277/bjdvd.2014.047

2. McGovern AP, Munro N, Watters K, Feher M. Profound weight reduction with GLP-1 agonist therapy: a delayed hyper-response. Pract Diabetes 2014;31:286-a.

3. Astrup A, Carraro R, Finer N, et al. Safety, tolerability and sustained weight loss over 2 years with the once-daily human GLP-1 analogue, liraglutide. Int J Obes 2012;36:843-54.

http://dx.doi.org/10.1038/ijo.2011.158

4. Wadden TA, Hollander $P$, Klein $S$, et al. Weight maintenance and additional weight loss with liraglutide after low-calorie-diet-induced weight loss: the SCALE Maintenance randomized study. Int J Obes 2013;37:1443-51. http://dx.doi.org/10.1038/ijo.2013.120

5. Vilsbøll $T$, Christensen M, Junker AE, Knop FK, Gluud LL. Effects of glucagon-like peptide-1 receptor agonists on weight loss: systematic review and meta-analyses of randomised controlled trials. BMJ 2012;344:d7771. http://dx.doi.org/10.1136/bmj.d7771

6. Jendle J, Nauck M, Matthews $D$, et al. Weight loss with liraglutide, a once-daily human glucagon-like peptide-1 analogue for type 2 diabetes treatment as monotherapy or added to metformin, is primarily as a result of a reduction in fat tissue. Diabetes Obes Metab 2009;11:1163-72. http://dx.doi.org/10.1111/j.1463-1326.2009.01158.x

7. Marre M, Shaw J, Brändle M, et al. Liraglutide, a once-daily human GLP-1 analogue, added to a sulphonylurea over 26 weeks produces greater improvements in glycaemic and weight control compared with adding rosiglitazone or placebo in subjects with type 2 diabetes (LEAD-1 SU). Diabet Med 2009;26:268-78.

http://dx.doi.org/10.1111/j.1464-5491.2009.02666.x

8. Bolinder J, Ljunggren Ö, Kullberg J, et al. Effects of dapagliflozin on body weight, total fat mass, and regional adipose tissue distribution in patients with type 2 diabetes mellitus with inadequate glycemic control on metformin. J Clin Endocrinol Metab 2011;97:1020-31. http://dx.doi.org/10.1210/jc.2011-2260

9. Ferrannini E, Ramos SJ, Salsali A, Tang W, List JF. Dapagliflozin monotherapy in type 2 diabetic patients with inadequate glycemic control by diet and exercise a randomized, double-blind, placebo-controlled, phase 3 trial. Diabetes Care 2010;33:2217-24

http://dx.doi.org/10.2337/dc10-0612

10. Kasichayanula S, Liu X, Shyu W, et al. Lack of pharmacokinetic interaction between dapagliflozin, a novel sodium-glucose transporter 2 inhibitor, and metformin, pioglitazone, glimepiride or sitagliptin in healthy subjects. Diabetes Obes Metab 2011;13:47-54. http://dx.doi.org/10.1111/j.1463-1326.2010.01314.x

11. Jensterle M, Pirs B, Goricar K, Dolzan V, Janez A. Genetic variation in GLP1 receptor is associated with interindividual differences in weight lowering potential of liraglutide in obese women with PCOS. 17th European Congress of Endocrinology, Endocrine Abstracts, 2015. http://dx.doi.org/10.1530/endoabs.37.ep590 